\title{
Incidence of maternal near miss and mortality cases in central India tertiary care centre and evaluation of various causes
}

\author{
Deepti Gupta, Arnab Nandi, Nazia Noor, Tulika Joshi, Meena Bhargava \\ Correspondence: Dr Deepti Gupta, Assistant Professor, Department of Obstetrics and \\ Gynaecology, Index Medical College, Indore, MP, India; Email - drspnagariya@gmail.com \\ Distributed under Creative Commons Attribution-Share Alike 4.0 International.
}

\begin{abstract}
Background: Analysis of maternal near miss provides a good opportunity for assessing the factors responsible for maternal mortality in this area. Objective: Incidence of maternal near miss and mortality cases in central India tertiary care centre and evaluation of various causes using WHO criteria. Material and Methods: It is an ongoing prospective observational study conducted in the department of Obstetrics and Gynaecology, Index medical college, Indore, MP from September 2015 to October 2016. The patients who fulfilled the WHO criteria of maternal near miss were enrolled; their clinical and investigation parameters were recorded. Results: During the study period a total 4786 deliveries were observed, out of that 4533 were live births, 74 were near miss cases and 15 maternal deaths. Twenty nine (39.1\%) of near miss cases were found in 15-20 year of age group while $53.33 \%$ cases of maternal death were found of same age group. Primipara cases were more in both near miss $(60.8 \%)$ and maternal death group $(60.0 \%)$. Majority of patients were in third trimester and underwent vaginal delivery. Among the causes of near miss events, hemorrhage was the leading cause followed by preeclampsia/eclampsia and sepsis. Conclusion: Near miss cases generally occur more frequently than maternal death and therefore a more reliable quantitative analysis can be carried out, which can provide more comprehensive profile of health system functioning. Identification of the obstacles and gaps in the health system and a coordinated approach to resolve these can ultimately lead to an improved health system.
\end{abstract}

Keywords: Maternal near miss, maternal death, maternal mortality indices.

Traditionally, the analysis of maternal deaths has been the criteria of choice for evaluating women's health and the quality of obstetric care. Due to the success of modern medicine such deaths have become very rare in developed country, which has led to an increased interest in analyzing so-called "near miss" events.

A maternal death is one of the most devastating events in obstetrics with widespread implications on both the family and the medical staff involved. Every woman goes through a risk for this sudden and unexpected event during pregnancy, childbirth and after delivery. According to World Health Organization (WHO), a maternal death is defined as death of a woman while pregnant or within 42 days of termination of pregnancy; irrespective of the duration and site of the pregnancy, from any cause related to or aggravated by the pregnancy or its management but not from accidental or incidental causes ${ }^{1}$. A maternal near miss case is defined as a woman

Received: 19 th September 2017. Accepted: 7 th December 2017.

Gupta D, Nandi A, Noor N, Joshi T, Bhargava M. Incidence of maternal near miss and mortality cases in central India tertiary care centre and evaluation of various causes. The New Indian Journal of OBGYN. 2018; 4(2): 112-6 
who nearly died but survived a complication that occurred during pregnancy, childbirth or within 42 days of termination of pregnancy ${ }^{1}$. In practical terms, women are considered near-miss cases when they survive lifethreatening conditions i.e. organ dysfunction. Severe maternal outcome (SMO) is the maternal near-miss cases and maternal death ${ }^{2}$. Despite therapeutic advances in medical science and a growing perception of the safety of childbirth; morbidity and mortality continue to occur in obstetrics especially in the developing countries like India $^{3}$. Fortunately, most of the obstetrical complications can be prevented or managed provided a timely and properly taken intervention is secured to the patient. Nearmiss cases share many characteristics with maternal death and can directly inform on obstacles that had to overcome after the onset of an acute complication. Corrective actions for identified problems can be taken to reduce mortality and long term morbidity ${ }^{4}$.

There are several advantages of investigating near miss events over events with fatal outcome -

- Near miss is more common than maternal dea ths ${ }^{5}$

- Their review is likely to yield useful information on the same pathways that lead to severe morbidity and death,

- Investigating the care received may be less threatening to providers because the woman survived

- One can learn from the women themselves since they can be interviewed about the care they received.

- All near misses should be interpreted as free lessons and opportunities to improve the quality of service provision ${ }^{6}$.

- It is also clear that maternal deaths merely are the tip of the iceberg of maternal disability. For every woman who dies, many more will survive but often suffer from lifelong disabilities ${ }^{\mathbf{1}}$.

The growing interest is reflected in an increasing number of systematic reviews on the prevalence of near miss.

Over the last decade, identification of cases of severe maternal morbidity has emerged as a promising complement or alternative to the investigation of maternal death. Maternal mortality rate is very high in our country including Madhya Pradesh. Although government is trying a lot to reduce maternal and infant mortality rate, still it is very high compared to the developed countries. Index Medical College is situated in outskirt of western MP and provides health services at very affordable cost. It receives a large number of obstetric patients daily from rural area. Many of them get admission in the hospital in a moribund state. While most of them survive but few patients lose their lives. A continuing study is being carried out on these critical patients to know the various factors related to maternal near miss and mortality cases in our set up.

India has made significant progress in reducing maternal mortality rate from 254 (SRS 2004-06) to 212 (SRS 2007-09) to 178 (SRS 2010-12) per 100,000 live birth ${ }^{7}$, however, there is a long way to go on this journey to meet the millennium development goals.

In this study, we aimed to determine the age and parity distribution of the cases, assess the causes of maternal near miss and maternal mortality, what interventions were taken to treat the patients and what is the outcome of affected cases.

Various indices like maternal near miss incidence ration per 1000 live birth, maternal near miss and mortality ratio, mortality index and maternal mortality rate were calculated.

\section{Methodology}

It is an ongoing prospective observational study conducted in the department of Obstetrics \& Gynaecology, Index medical college, Indore, Madhya Pradesh from September 2015 to October 2016. We followed "The WHO near-miss approach for maternal health" for this study. Any patient who met any one of the WHO inclusion criteria mentioned below was included in study and all cases of maternal death during this period were included. Data have been collected from the patients having Near Miss Mortality event during the hospital stay or immediately following maternal death. Data collection was done with a pro-forma prepared for the study.

\section{WHO Inclusion criteria}

According to WHO, any of the following conditions that is/are present during their stay at the health-care facility would be eligible. Women that develop those conditions unrelated to pregnancy (i.e. not during pregnancy or 42 days after termination of pregnancy) are 
not eligible. Women who are already dead when they are brought to the health-care facility or those who die on arrival at the facility should be included because they are likely to represent cases involving a major delay in accessing care. The eligibility is not restricted by gestational age at which complications occurred (i.e. women having abortions or ectopic pregnancies and presenting with any of the inclusion criteria are eligible).

The conditions are as follows-

1. Severe maternal complications

- Severe postpartum haemorrhage

- Severe pre-eclampsia and eclampsia

- Sepsis or severe systemic infection

- Ruptured uterus

- Severe complications of abortion

2. Critical interventions or intensive care unit use

- Admission to intensive care unit

- Interventional radiology

- Laparotomy (includes hysterectomy, excludes caesarean section)

- Use of blood products

3. Life-threatening conditions (near-miss criteria)

- Cardiovascular dysfunction - Shock, cardiac arrest (absence of pulse/ heart beat and loss of consciousness), use of continuous vasoactive drugs, cardiopulmonary resuscitation, severe hypoperfusion.

-Neurological dysfunction - Prolonged unconsciousness (lasting $\geq 12$ hours)/coma (including metabolic coma), stroke, uncontrollable fits/status epilepticus

-Uterine dysfunction -- Uterine haemorrhage or infection leading to hysterectomy

4. Maternal vital status - Maternal death.

Maternal near- miss and maternal mortality cases were identified among women with pregnancy related complications whose diagnosis met the above mentioned criteria and who were admitted in our hospital . Patient characteristics including age, parity; gestational age at admission and surgical intervention taken to save the life of the patient were also noted. Investigations were done for anaemia, septicaemia, eclampsia and for organ system dysfunction/ failure. Data was collected for determining the nature of obstetric complication, presence of organ system dysfunction and timing of near miss events with respect to admission. Fetal outcome and mode of delivery was also noted. Detailed information of maternal mortalities for the underlying cause and time period was noted. The descriptive analysis of the collected data was done and the results were given in percentages. The incidence of near miss cases and maternal death to near miss ratio was calculated. Various indices related to maternal health were calculated-

1. Maternal near miss incidence ratio per 1000 live births.

2. Maternal near miss and mortality ratio

3. Mortality index $=M D /(M N M+M D) \times$ 100

4. Maternal Mortality rate

\section{Results}

During the study period a total 4786 deliveries were observed, out of that 4533 were live births, 74 were near miss cases and 15 maternal deaths. Table 1 shows $39.1 \%$

Table 1: Distribution of cases on basis of age, parity, gestational age, modes of termination

\begin{tabular}{|c|c|c|c|}
\hline Categories & & $\begin{array}{l}\text { Near Miss } \\
(\mathbf{N}=74) \\
\mathbf{N}(\%)\end{array}$ & $\begin{array}{l}\text { Maternal } \\
\text { Death } \\
(\mathbf{N}=15) \\
N(\%)\end{array}$ \\
\hline Age of & $15-20$ & $29(39.1 \%)$ & $8(53.33 \%)$ \\
\hline patient & $21-25$ & $22(29.7 \%)$ & $3(33.33 \%)$ \\
\hline \multirow[t]{2}{*}{ years } & $26-30$ & $14(18.9 \%)$ & $1(6.66 \%)$ \\
\hline & $>30$ & $9(12.1 \%)$ & $3(20.0 \%)$ \\
\hline \multirow[t]{2}{*}{ Parity } & Primi & $45(60.8 \%)$ & $9(60.0 \%)$ \\
\hline & Multi & $29(39.1 \%)$ & $6(40.0 \%)$ \\
\hline \multirow{4}{*}{$\begin{array}{l}\text { Gestational } \\
\text { age in } \\
\text { weeks }\end{array}$} & $<12$ & $9(12.1 \%)$ & \\
\hline & $12-28$ & $5(6.75 \%)$ & $1(6.66 \%)$ \\
\hline & $>28$ & $52(70.2 \%)$ & $7(46.66 \%)$ \\
\hline & Postnatal & $8(10.8 \%)$ & $7(46.66 \%)$ \\
\hline \multirow{5}{*}{$\begin{array}{l}\text { Modes of } \\
\text { termination } \\
\text { of } \\
\text { pregnancy }\end{array}$} & $\begin{array}{l}\text { Vaginal } \\
\text { delivery }\end{array}$ & $47(63.5 \%)$ & $12(80.0 \%)$ \\
\hline & LSCS & $18(24.3 \%)$ & - \\
\hline & $\begin{array}{l}\text { Laparotomy } \\
\text { for ruptured } \\
\text { uterus } \\
\text { Laparotomy }\end{array}$ & $5(6.75 \%)$ & $1(6.66 \%)$ \\
\hline & $\begin{array}{l}\text { for ruptured } \\
\text { ectopic }\end{array}$ & $2(2.7 \%)$ & $2(13.33 \%)$ \\
\hline & $\begin{array}{l}\text { Dilatation and } \\
\text { evacuation }\end{array}$ & $2(2.7 \%)$ & . \\
\hline
\end{tabular}

of near miss cases were found in 15-20 year of age group while $53.33 \%$ cases of maternal death were found of same age group. Primipara cases were more in both near 
miss $(60.8 \%)$ and maternal death group $(60.0 \%)$ in comparison to multipara group. Majority of patients were

Table 2: Distribution of cases on the basis of causes

\begin{tabular}{lllll}
\hline Causes & \multicolumn{2}{c}{ Near Miss } & \multicolumn{2}{c}{ Maternal Death } \\
& $\mathrm{N}(74)$ & $\%$ & $\mathrm{~N}(15)$ & $\%$ \\
\hline Hemorrhage & 30 & $40.5 \%$ & 01 & $6.66 \%$ \\
$\begin{array}{l}\text { Preeclampsia/ } \\
\text { Eclampsia }\end{array}$ & 18 & $24.3 \%$ & 05 & $33.3 \%$ \\
$\begin{array}{l}\text { Sepsis } \\
\text { Ruptured Uterus }\end{array}$ & 05 & $13.5 \%$ & 02 & $13.33 \%$ \\
$\begin{array}{l}\text { Malaria } \\
\text { Hepatitis }\end{array}$ & 03 & $4.75 \%$ & 02 & $13.33 \%$ \\
$\begin{array}{l}\text { Severe Anemia } \\
\text { Diarrhoea with }\end{array}$ & 06 & $1.35 \%$ & 01 & $6.66 \%$ \\
shock & 01 & $1.35 \%$ & 01 & $6.66 \%$ \\
\hline
\end{tabular}

in third trimester in near miss group $(70.2 \%)$ while maternal death were equal in third trimester $(46.6 \%)$ and post natal period (46.6\%). Table 1 shows that majority patients of both groups were underwent vaginal delivery, $63.5 \%$ in near miss and $80.0 \%$ in maternal death group respectively.

Table 2 summarizes the causes of near miss and maternal mortality cases. Among the causes of near miss events, hemorrhage was the leading cause $(40.5 \%)$,

Table 3: Maternal near miss incidence ratio per 1000 live birth and mortality index

\begin{tabular}{|c|c|c|c|}
\hline Causes & $\begin{array}{l}\text { Total } \\
\text { NM } \\
\text { cases }\end{array}$ & $\begin{array}{l}\text { NM cases } \\
\text { in } 1000 \\
\text { live birth }\end{array}$ & $\begin{array}{l}\text { Mortality index= } \\
\text { MD/(MNM+MD) } \\
\times 100\end{array}$ \\
\hline $\begin{array}{l}\text { Hemorrhage } \\
\text { Preeclampsia/ }\end{array}$ & 30 & 6.61 & 3.22 \\
\hline Eclampsia & 18 & 3.97 & 21.73 \\
\hline $\begin{array}{l}\text { Sepsis } \\
\text { Ruptured }\end{array}$ & 10 & 2.20 & 16.66 \\
\hline Uterus & 05 & 1.10 & 28.57 \\
\hline Malaria & 03 & 0.66 & 25.00 \\
\hline Hepatitis & 01 & 0.22 & 50.00 \\
\hline Severe Anemia & 06 & 1.32 & 25.00 \\
\hline $\begin{array}{l}\text { Diarrhoea with } \\
\text { shock }\end{array}$ & 01 & 0.22 & 50.00 \\
\hline
\end{tabular}

followed by pre eclampsia/ eclampsia $(24.3 \%)$ and sepsis $(13.5 \%)$. In maternal mortality group, pre eclampsia/ eclampsia $(33.3 \%)$ are leading cause followed by sepsis $(13.33 \%)$ and severe anemia $(13.33 \%)$.

Table 3 summarizes the near miss cases in 1000 live births and mortality index on the basis of causes. This study shows that mortality index is very high in our hospital with highest for patients came in shock $(50.0 \%)$ and diagnosed with hepatitis (50\%).

\section{Discussion}

Near miss cases generally occur more frequently than maternal death and therefore a more reliable quantitative analysis can be carried out, which can provide more comprehensive profile of health system functioning.

Identification of the obstacles and gaps in the health system and a coordinated approach to resolve these can ultimately lead to an improved health system. Different studies from India and other developing and developed countries have reported prevalence of near miss of $14.1 \%$, $10.1 \%$ and $8.2 \%$ respectively ${ }^{2}$.

This study is first attempt to document both maternal near miss and mortality in Central India region. The maternal near miss incidence ratio (MNMR) was 16.32/1000 live birth in our hospital. Various available studies show the similar trend and it is varies between 1540/1000 live births in the developing countries ${ }^{\mathbf{1 , 3 , 8}}$. The high maternal near miss ratio observed in the present study indicates the frequent occurrence of near miss in this population. As this is a tertiary referral center which receives critical patients from all surrounding districts.

The major causes of potentially life threatening conditions and near miss cases were hemorrhage (40.5 $\%)$, preeclampsia/ eclampsia (24.3\%), sepsis (13.5\%), severe anemia $(8.10 \%)$, ruptured uterus $(6.75 \%)$, malaria $(4.05 \%)$, hepatisis $(1.35 \%)$ and shock due to diarrhea $(1.35 \%)$. Hemorrhage was the main diagnosis associated with near miss cases, coinciding with the various studies conducted in developed countries ${ }^{9}$ however it is differs from Brazilian study which shows preeclampsia was the leading cause ${ }^{\mathbf{1 0}}$.

Total 21 deaths were observed in our study and pre eclampsia/ eclampsia $(33.3 \%)$ was the leading cause followed by sepsis $(14.28 \%)$ and severe anemia (14.28 $\%$ ). Most of the patient of maternal death group came to our hospital at terminal stage and died within $24 \mathrm{hrs}$.

Maternal mortality index $(\mathrm{MI}=\mathrm{MD} /(\mathrm{MNM}+\mathrm{MD}) *$ 100 ) in our set up is 22.10 . This is very high. Near miss to mortality ratio was 3.52:1 which means for every 3-4 life threatening conditions there was one maternal death. This ratio is similar to those of African country where the range is $5-12: 1^{11}$. 
Our medical college is a tertiary referral center covering remote area of MP and most of the cases are referred in already moribund state. The higher the mortality index, more the woman with the life threatening conditions dies (low quality of care). The high mortality index in our center is due to inadequate utilization of resources, poor antenatal care, delayed referrals, poor transport facilities and lack of skilled personnel at subcenter, PHC and CHC levels.

\section{Conclusion}

The major causes of near miss cases were similar to the causes of maternal mortality and can directly inform about obstacles that had to overcome after the onset of acute complication. Hypertension and haemorrhage are the leading cause of near miss events. As near miss analysis indicates quality of health care, it is worth presenting in national indices and need for development of an effective audit system for both near miss and mortality cases. The audit system will allows us to identify the problems in early stage and we can initiate various corrective measures to reduce morbidity and mortality.

\section{Conflict of interest: None. Disclaimer: Nil.}

\section{References}

1.Say L, Souza JP, Pattinson RC. WHO working group on Maternal Mortality and Morbidity classifications. Maternal near miss - towards a standard tool for monitoring quality of maternal health care. Best Pract Res Clin Obstet Gynaecol. 2009 Jun; 23(3): 287-96.

2.Chhabra P. Maternal Near Miss: An Indicator for Maternal Health and Maternal Care. Indian J Community Med. 2014; 39(3): 132-7.

3.Souza JP, Cecatti JG, Parpinelli MA, Serruya SJ, Amaral E. Appropriate criteria for identification of near-miss maternal morbidity in tertiary care facilities: a cross sectional study. BMC Pregnancy and Childbirth. 2007; 7(20): 1-8.
4.World Health Organization. Evaluating the quality of care for severe pregnancy complications -The WHO near- miss approach for maternal health. Geneva: World Health Organization; 2011.

5.Minkauskiene M. Incidence/prevalence of severe maternal morbidity - a literature review. Review prepared for the 12th Postgraduate Course in Reproductive Medicine and Biology. WHO; Geneva, Switzerland; 2017. [Internet] Available from: https:// www.gfmer.ch/Endo/Course 2003/Severe_ maternal\%20morbidity_review.htm

6.Minkauskiene M, Nadisauskiene R, Padaiga1 Z, Makari S. Systematic review on the incidence and prevalence of severe maternal morbidity. Medicina. 2004; 40 (4): 299-309.

7.Sample Registration System (SRS). Special Bulletin on Maternal Mortality in India 2007-09. New Delhi: Office of Registrar General, India; 2011.

8.Prual A, Huguet D, Garbin O, Rab'e G. Severe obstetric morbidity of the third trimester, delivery and early puerperium in Niamey (Niger). African Journal of Reproductive Health. 1998; 2(1); 10-9.

9.Zanette E, Parpinelli MA, Surita FG, Costa ML, Haddad SM, Sousa ML, E Silva JL, Souza JP, Cecatti JG. Maternal near miss and death among women with severe hypertensive disorders: A Brazilian multicenter surveillance study. Reprod Health. 2014; 11(1): 4.

10.Pattinson RC, Hall M. Near misses: a useful adjunct to maternal death enquiries. Br Med Bull. 2003; 67: 231-43.

11.Van Roosmalen J, Zwart J. Severe acute maternal morbidity in high-income countries. Best practice and research: Clinical Obstetrics and Gynaecology. 2009; 23(3): 297-304.

\section{Deepti Gupta ${ }^{1}$, Arnab Nandi ${ }^{2}$, Nazia Noor ${ }^{3}$, Tulika Joshi ${ }^{4}$, Meena Bhargava ${ }^{5}$}

${ }^{1}$ Assistant Professor; ${ }^{2}$ Senior Registrar, ${ }^{3}$ Senior Registrar; ${ }^{4}$ Assistant Professor, ${ }^{5}$ Professor, Department of Obstetrics and Gynaecology Index Medical College, Indore MP, India. 